\title{
Penilaian dan Penanganan Kerusakan Perkerasan Jalan Mercedes Benz, Kecamatan Gunung Putri, Kabupaten Bogor, Jawa Barat
}

\author{
Beryl Visa Ariza dan Cahya Buana \\ Departemen Teknik Sipil, Institut Teknologi Sepuluh Nopember (ITS) \\ e-mail: cahya_b@ce.its.ac.id
}

\begin{abstract}
Abstrak-Kondisi Jalan Mercedes Benz sepanjang 3,4 km ini mengalami kerusakan berupa jalan bergelombang, berlubang, dan konstruksi beton yang hancur. Penyebab utamanya adalah perubahan pemanfaatan lahan menjadi lahan industri yang menimbulkan banyaknya aktivitas kendaraan berat yang melintas dan berdampak pada jalan ini. Berdasarkan kondisi tersebut maka perlu dilakukan perbaikan pada jalan tersebut. Pertama dilakukan peninjauan kerusakan jalan dengan cara visual dan riding quality untuk mengetahui nilai dan tingkat kerusakan yang terjadi pada jalan tersebut. Kemudian perlu diketahui karakteristik lalu lintas pada saat ini dan analisis karakteristik lalu lintas sesuai umur rencana. Lalu, dilakukan perencanaan tebal struktur perkerasan lentur dan kaku. Dan analisis perbandingan kedua jenis perkerasan tersebut untuk menjadi rekomendasi perbaikan yang sesuai pada jalan tersebut. Pemilihan jenis perkerasan yang sesuai berdasarkan biaya konstruksi dan pemeliharaan yang lebih rendah antara kedua jenis perkerasan tersebut. Dari hasil perhitungan dan analisis tersebut didapatkan perkerasan kaku dengan umur rencana 40 tahun dengan tebal pelat beton $28,5 \mathrm{~cm}$, lapis pondasi LMC $10 \mathrm{~cm}$, dan lapis drainase $15 \mathrm{~cm}$ sebagai rekomendasi konstruksi perkerasan jalan yang sesuai untuk menangani kerusakan Jalan Mercedes Benz. Dengan biaya konstruksi sebesar $R p$ 3.722.769,- $/ \mathrm{m}^{3}$ dan biaya pemeliharaan Rp 638.793,- $/ \mathrm{m}^{3}$.
\end{abstract}

Kata Kunci-Kerusakan Jalan, Perkerasan Lentur, Perkerasan Kaku, Perbandingan Perkerasan.

\section{PENDAHULUAN}

$\mathbf{J}^{2}$ ALAN adalah seluruh bagian jalan, termasuk bangunan pelengkap dan perlengkapannya yang diperuntukkan bagi lalu lintas umum yang berada pada permukaan tanah, di atas permukaan tanah dan/atau air, serta di atas permukaan air, kecuali jalan rel dan jalan kabel (UU No.22 Tahun 2009) [1]. Perkerasan jalan adalah lapisan perkerasan yang terletak di antara lapisan tanah dasar dan roda kendaraan yang befungsi memberikan pelayanan kepada transportasi. Ada beberapa jenis perkerasan jalan berdasarkan bahan pengikatnya menurut Sukirman (1999), yaitu perkerasan lentur (flexible pavement), perkerasan kaku (rigid pavement), dan perkerasan komposit (composite pevement) [2].

Saat ini kerusakan jalan terutama pada konstruksi perkerasan banyak terjadi. Salah satunya di Jalan Mercedes Benz sepanjang 3,4 kilometer, lebar jalan 7 meter, dan tipe jalan 2/2UD berdasarkan administrasi pemerintahan dikategorikan sebagai jalan kabupaten dan jalan kelas III A. Dan kondisinya saat ini mengalami kerusakan jalan berupa jalan bergelombang, berlubang besar, dan konstruksi beton yang hancur. Beberapa penyebab kerusakan tersebut adalah

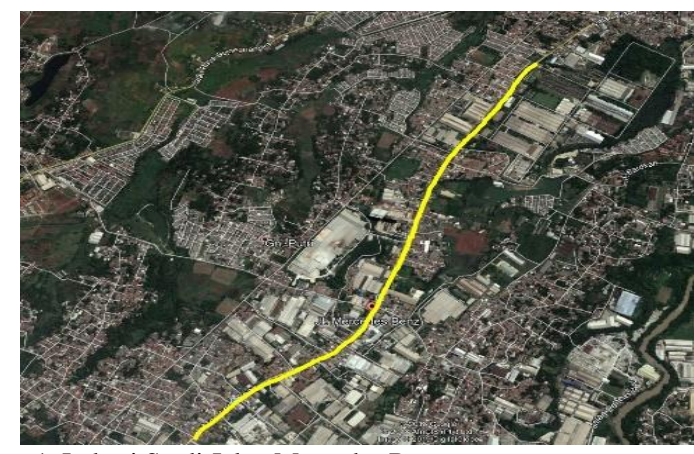

Gambar 1. Lokasi Studi Jalan Mercedes Benz.

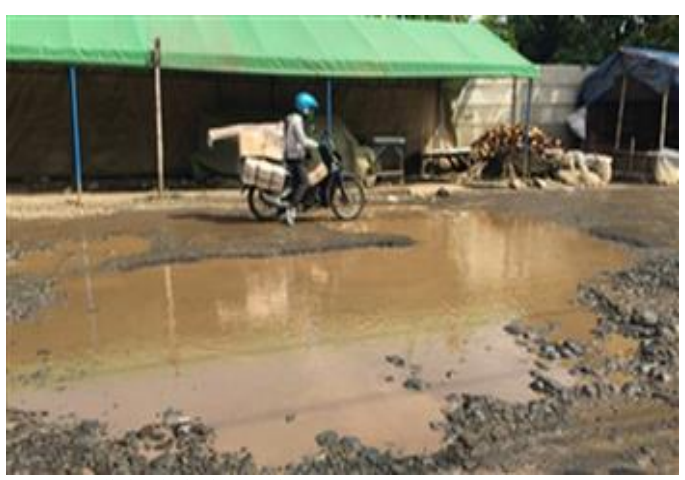

Gambar 2. Kondisi Eksisting Jalan Mercedes Benz.

pemanfaatan lahan di sekitar jalan yang merupakan kawasan industri menyebabkan aktivitas lalu lintas kendaraan terutama kendaraan besar akan sangat sering terjadi dan berpengaruh langsung terhadap kondisi jalan. Lalu, perawatan jalan yang kurang menyeluruh dan terkesan hanya dilakukan bersifat sementara karena setelah beberapa bulan jalan kembali mengalami kondisi yang sama yaitu rusak. Dan beban lalu lintas aktual yang terjadi di Jalan Mercedes Benz ini kemungkinan melebihi kapasitas rencana.

Berdasarkan hal tersebut, kerusakan-kerusakan perkerasan jalan di Jalan perlu diperbaiki. Dalam hal ini permasalahan yang akan diselesaikan mengenai kekuatan dari Perkerasan Jalan Mercedes Benz dalam menerima beban aktual yang melebihi persayaratan yang ada. Untuk mengetahui jenis perkerasan apa yang paling tepat digunakan, akan dilakukan perbandingan perencanaan perkerasan lentur dan perkerasan kaku. Pertama, perlu diketahui dahulu karakteristik lalu lintas berdasarkan data survei lalu lintas. Apabila karakteristik lalu lintas sudah diketahui, dilanjutkan dengan perencanaan tebal masing-masing perkerasan serta analisis biaya konstruksi dan pemeliharaannya. Sehingga dapat diketahui jenis perkerasan 


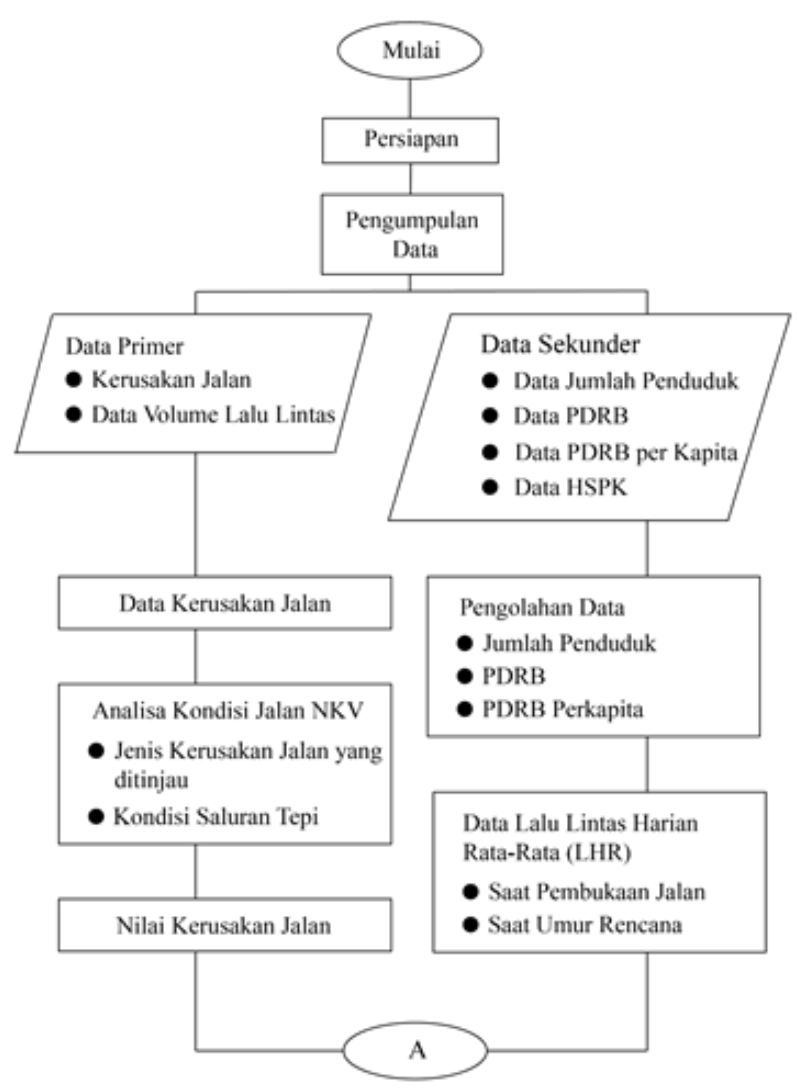

Gambar 4. Bagin Alir Penyusunan Studi.

apa yang paling sesuai dan paling ekonomis untuk perbaikan kerusakan perkerasan jalan di Jalan Mercedes Benz. Lokasi Studi Jalan Mercedes Benz. Dapat dilihat pada Gambar 1. Kondisi Eksisting Jalan Mercedes Benz. Dapat dilihat pada Gambar 2.

\section{A. Permasalahan Utama}

Bagaimana kondisi kerusakan jalan dan jenis perkerasan apa yang sesuai untuk perbaikan kerusakan di Jalan Mercedes Benz?

\section{B. Detail Permasalahan}

1. Bagaimana kondisi lalu lintas di Jalan Mercedes Benz saat ini?

2. Berapa nilai kerusakan Jalan Mercedes Benz saat ini?

3. Berapa tebal struktur perkerasan lentur yang dibutuhkan untuk perbaikan kerusakan perkerasan jalan di Jalan Mercedes Benz dengan umur rencana 20 tahun?

4. Berapa tebal struktur perkerasan kaku yang dibutuhkan untuk perbaikan kerusakan perkerasan jalan di Jalan Mercedes Benz dengan umur rencana 40 tahun?

5. Berapa biaya konstruksi dan pemeliharaan yang diperlukan untuk masing-masing struktur perkerasan lentur dan kaku?

6. Jenis perkerasan apakah yang memiliki biaya lebih rendah untuk perbaikan kerusakan perkerasan jalan di Jalan Mercedes Benz ini?

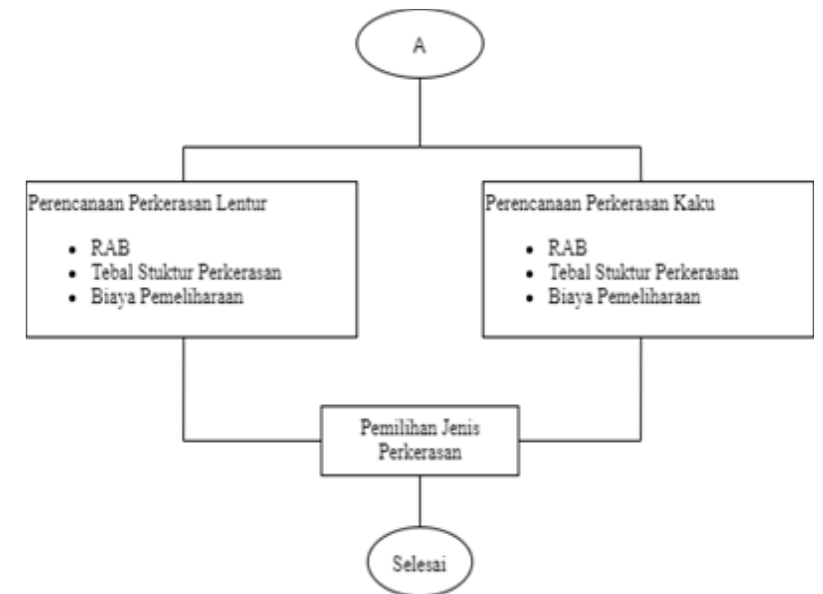

Gambar 3. Lanjutan Bagin Alir Penyusunan Studi.

Tabel 1.

Jenis kerusakan dan Faktor pengali

\begin{tabular}{clc}
\hline \multicolumn{3}{c}{ Jenis kerusakan dan Faktor pengali } \\
\hline Kategori & $\begin{array}{c}\text { Jenis Kerusakan Permukaan } \\
\text { Jalan }\end{array}$ & Faktor Pengali \\
\hline Kategori I & $\begin{array}{l}\text { Potholes } \\
\text { Ravelling-Weathering, } \\
\text { Alligator Cracking \& Profile } \\
\text { Distortion } \\
\text { (Depression, Corrugation, Up- }\end{array}$ & 6 \\
Kategori III & $\begin{array}{l}\text { Transverse Cracks, } \\
\text { Longitudinal Cracks, } \\
\text { Block Cracks, Rutting } \\
\text { Kategori IV }\end{array}$ & $\begin{array}{l}\text { Pacthing, Flushing, Edge } \\
\text { Cracking }\end{array}$ \\
\hline \hline
\end{tabular}

Tabel 2.

Perhitungan Nilai Kerusakan Jalan pada Segmen 10

\begin{tabular}{|c|c|c|c|c|}
\hline Kategori & $\begin{array}{c}\text { Jenis } \\
\text { Kerusakan }\end{array}$ & $\begin{array}{l}\text { Nilai } \\
\text { dalam } \\
\text { Form }\end{array}$ & $\begin{array}{l}\text { Faktor } \\
\text { Pengali }\end{array}$ & $\begin{array}{c}\text { Nilai } \\
\text { Kerusakan }\end{array}$ \\
\hline \multirow{2}{*}{ I } & \multirow{2}{*}{ Potholes } & 6 & \multirow{2}{*}{6} & 36 \\
\hline & & 2 & & 12 \\
\hline II & Reveling & 2 & 2 & 4 \\
\hline II & $\begin{array}{l}\text { Aligator } \\
\text { Cracking }\end{array}$ & 2 & 2 & 4 \\
\hline III & $\begin{array}{c}\text { Block } \\
\text { Cracking }\end{array}$ & 3 & 1 & 3 \\
\hline \multirow{2}{*}{ III } & \multirow{2}{*}{ Rutting } & 3 & \multirow{2}{*}{1} & 3 \\
\hline & & 2 & & 2 \\
\hline \multirow[t]{2}{*}{ IV } & $\begin{array}{c}\text { Edge } \\
\text { Direction }\end{array}$ & 2 & 0,5 & 1 \\
\hline & \multicolumn{2}{|c|}{ Total Nilai Kerusakan } & & 65 \\
\hline
\end{tabular}

\section{METODOLOGI}

\section{A. Tahapan Umum}

Secara umum tahapan dalam penyusunan Studi ini adalah:

1. Tahap Persiapan

2. Tahap Pengumpulan Data

3. Tahap Analisis

\section{B. Tahap Persiapan}

Tahap Persiapan adalah melakukan studi literatur. Literatur yang digunakan untuk menilai kerusakan jalan [3].

Lalu, untuk panduan survei lalu lintas menggunakan Modul RDE-08: Rekayasa Lalu Lintas [4]. Kemudian, untuk merencanakan tebal struktur perkerasan menggunakan Manual Desain Perkerasan Jalan Nomor 04/SE/Db/2017 [5]. 
Tabel 3.

Kriteria Riding Quality

\begin{tabular}{|c|c|c|}
\hline Riding Quality & Keterangan & Nilai \\
\hline $\mathrm{RQ}_{1}:$ Excellent & $\begin{array}{l}\text { Kecepatan batas nyaman } \\
\text { Tanpa mengalami goncangan }\end{array}$ & 1 \\
\hline $\mathrm{RQ}_{2}:$ Good & $\begin{array}{l}\text { Kecepatan batas ada goncangan } \\
\text { Satu atau dua tempat terasa kasar }\end{array}$ & 2 \\
\hline $\mathrm{RQ}_{3}:$ Fair & $\begin{array}{l}\text { Kecepatan batas ada goncangan } \\
\text { Lebih dari dua tempat terasa kasar }\end{array}$ & 3 \\
\hline $\mathrm{RQ}_{4}:$ Poor & $\begin{array}{l}\text { Kecepatan di bawah batas pada situasi tertentu Jika terpaksa pengemudi menghindar dari } \\
\text { jalur karena bahaya kekasaran dan goncangan terasa sepanjang jalan. }\end{array}$ & 4 \\
\hline $\mathrm{RQ}_{5}$ : Very Poor & Kecepatan batas sulit, tidak mungkin dicapai sepanjang ruas jalan yang ditinjau & 5 \\
\hline
\end{tabular}

Tabel 4.

Nilai Kondisi Drainase pada Segmen 10

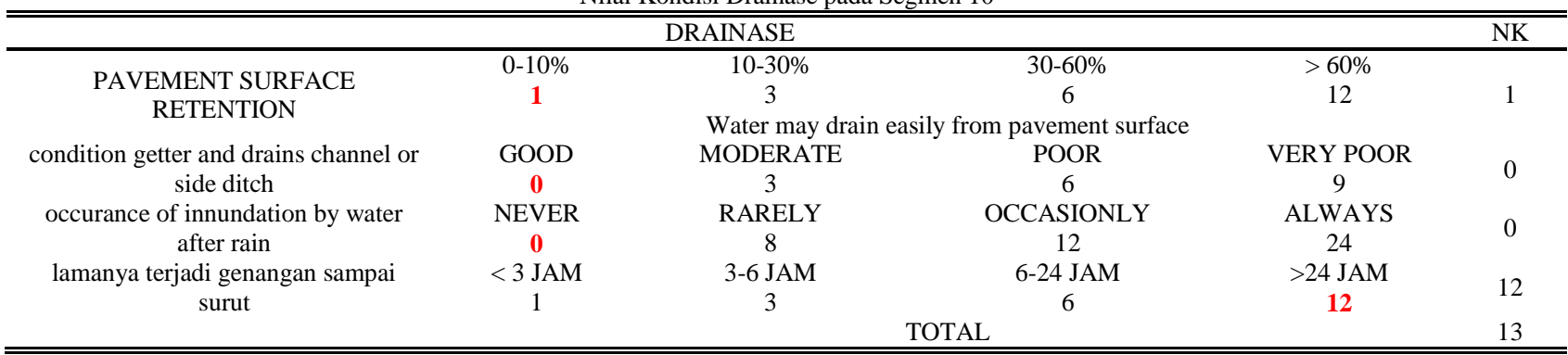

Tabel 5.

LHR Tahun Survei (2019)

\begin{tabular}{|c|c|c|c|}
\hline Gol & Kode & Ket & LHR (2019) \\
\hline 1 & & Total & 10174 \\
\hline 2 & 1.1 & Total & 2340 \\
\hline 3 & 1.1 & Total & 246 \\
\hline 4 & 1.1 & Total & 17 \\
\hline $5 \mathrm{a}$ & 1.1 & Total & 10 \\
\hline $5 b$ & 1.2 & Total & 10 \\
\hline $6 a$ & 1.1 & Total & 278 \\
\hline $6 \mathrm{~b} .1$ & $1.2 \mathrm{~L}$ & Total & 281 \\
\hline \multirow{2}{*}{$6 b .2$} & \multirow{2}{*}{$1.2 \mathrm{H}$} & Total & 88 \\
\hline & & Kosong & 27 \\
\hline \multirow{2}{*}{ 7a.1 } & \multirow{2}{*}{1.22} & Total & 113 \\
\hline & & Kosong & 13 \\
\hline \multirow{2}{*}{$7 a .2$} & \multirow{2}{*}{$1,2-2$} & Total & 19 \\
\hline & & Kosong & 14 \\
\hline $7 b$ & $1,22+22$ & Total & 0 \\
\hline $7 c 3$ & $1,22-222$ & Total & 102 \\
\hline \multirow{2}{*}{$7 \mathrm{c} 2.1$} & \multirow{2}{*}{$1,2-22$} & Total & 17 \\
\hline & & Kosong & 8 \\
\hline \multirow{3}{*}{$7 \mathrm{c} 2.2$} & \multirow{2}{*}{$1,2+22$} & Total & 19 \\
\hline & & Kosong & 1 \\
\hline & Total & & 13777 \\
\hline
\end{tabular}

Tabel 6.

Pertumbuhan Penduduk Kabupaten Bogor

\begin{tabular}{ccc}
\hline \hline Tahun & Jumlah penduduk & $\mathrm{i}(\%)$ \\
\hline 2014 & 5331149 & \\
2015 & 5459668 & 2.41 \\
2016 & 5587390 & 2.34 \\
2017 & 5715009 & 2.28 \\
2018 & 5840907 & 2.20 \\
& Rata-Rata & 2.31 \\
\hline \hline
\end{tabular}

Dan perhitungan biaya menggunakan Peraturan Kementerian PUPR Nomor 28/PRT/M/2016 [6].

\section{Tahap Pengumpulan Data}

Jenis data yang digunakan pada Studi ini terdiri dari:

1. Data primer yang diperoleh dari hasil pengamatan langsung di lapangan, yaitu :

a. Data lalu lintas harian rata-rata (LHR) dengan melakukan survei langsung dengan 2 surveyor selama $1 \times 12,5$ jam di lokasi studi.

b. Data kerusakan jalan dengan riding quality dilakukan menggunakan roda 4 dengan kecepatan
Tabel 7.

Prediksi Jumlah Kendaraan pada Tahun 2060

\begin{tabular}{|c|c|c|c|c|c|}
\hline Gol & Kode & Ket & $\begin{array}{l}\text { LHR } \\
(2019) \\
\end{array}$ & $\begin{array}{c}\text { LHR } \\
(2060) \\
\end{array}$ & KEND/JAM \\
\hline 1 & & Total & 10174 & 188266 & 7844 \\
\hline 2 & 1.1 & Total & 2340 & 43301 & 1804 \\
\hline 3 & 1.1 & Total & 246 & 627 & 26 \\
\hline 4 & 1.1 & Total & 17 & 43 & 2 \\
\hline $5 a$ & 1.1 & Total & 10 & 25 & 1 \\
\hline $5 b$ & 1.2 & Total & 10 & 25 & 1 \\
\hline $6 a$ & 1.1 & Total & 278 & 13121 & 547 \\
\hline $6 \mathrm{~b} .1$ & $1.2 \mathrm{~L}$ & Total & 281 & 13263 & 553 \\
\hline \multirow{2}{*}{$6 \mathrm{~b} .2$} & \multirow{2}{*}{$1.2 \mathrm{H}$} & Total & 88 & 4153 & 173 \\
\hline & & Kosong & 27 & 1274 & 53 \\
\hline \multirow{2}{*}{$7 a .1$} & \multirow{2}{*}{1.22} & Total & 113 & 5333 & 222 \\
\hline & & Kosong & 13 & 614 & 26 \\
\hline \multirow{2}{*}{$7 \mathrm{a} .2$} & \multirow{2}{*}{$1,2-2$} & Total & 19 & 897 & 37 \\
\hline & & Kosong & 14 & 661 & 28 \\
\hline $7 b$ & $1,22+22$ & Total & 0 & 0 & 0 \\
\hline $7 \mathrm{c} 3$ & $\begin{array}{l}1,22- \\
222\end{array}$ & Total & 102 & 4814 & 201 \\
\hline \multirow{2}{*}{$7 \mathrm{c} 2.1$} & \multirow{2}{*}{$1,2-22$} & Total & 17 & 802 & 33 \\
\hline & & Kosong & 8 & 378 & 16 \\
\hline \multirow{3}{*}{$7 \mathrm{c} 2.2$} & \multirow{2}{*}{$1,2+22$} & Total & 19 & 897 & 37 \\
\hline & & Kosong & 1 & 47 & 2 \\
\hline & Total & & 13777 & 278543 & 11606 \\
\hline
\end{tabular}

batas $40 \mathrm{~km} / \mathrm{jam}$.

c. Data kerusakan jalan yang ditinjau secara visual dilakukan dengan pengukuran langsung di jalan tersebut menggunakan meteran, mistar, dan walking dister.

d. Data kondisi drainase dilakukan bersamaan dengan survei visual.

2. Data sekunder yang diperoleh dari beberapa sumber yang telah ada, yaitu :

a. Data jumlah penduduk yang digunakan untuk meramalkan besarnya faktor pertumbuhan bus dan angkutan umum.

b. Data produk domestik regional bruto (PDRB) yang digunakan untuk meramalkan besarnya faktor pertumbuhan truk dan barang.

c. Data produk domestik regional bruto per kapita (PDRB per Kapita) yang digunakan untuk meramalkan besarnya faktor petumbuhan kendaraan 
Tabel 8 .

Hasil Perhitungan CESAL 2040

\begin{tabular}{|c|c|c|c|c|c|c|c|c|}
\hline KODE & KET & LHR (2020) & $\mathrm{R}$ & VDF TABEL & $\mathrm{DD}$ & DL & 365 & Cesal \\
\hline 1.2 & Total & 10.23 & 20.04 & 0.2 & 1 & 1 & 365 & 14970 \\
\hline 1.1 & Total & 10.23 & 20.04 & 1 & 1 & 1 & 365 & 74850 \\
\hline $1.2 \mathrm{~L}$ & Total & 305.40 & 20.19 & 0.8 & 1 & 1 & 365 & 1800350 \\
\hline \multirow{2}{*}{$1.2 \mathrm{H}$} & Total & 308.70 & 20.19 & 1.7 & 1 & 1 & 365 & 3867028 \\
\hline & Kosong & 96.67 & 20.19 & 0.8 & 1 & 1 & 365 & 569895 \\
\hline \multirow{2}{*}{1.22} & Total & 29.66 & 20.19 & 0.8 & 1 & 1 & 365 & 174854 \\
\hline & Kosong & 124.14 & 20.19 & 11.2 & 1 & 1 & 365 & 10245157 \\
\hline \multirow{2}{*}{$1,2-2$} & Total & 14.28 & 20.19 & 11.2 & 1 & 1 & 365 & 1178646 \\
\hline & Kosong & 20.87 & 20.19 & 64.4 & 1 & 1 & 365 & 9905162 \\
\hline $1,22+22$ & Total & 15.38 & 20.19 & 64.4 & 1 & 1 & 365 & 7298541 \\
\hline $1,22-222$ & Total & 112.05 & 20.19 & 93.7 & 1 & 1 & 365 & 77368093 \\
\hline \multirow{2}{*}{$1,2-22$} & Total & 18.68 & 20.19 & 33.2 & 1 & 1 & 365 & 4568874 \\
\hline & Kosong & 8.79 & 20.19 & 33.2 & 1 & 1 & 365 & 2150058 \\
\hline \multirow{3}{*}{$1,2+22$} & Total & 20.87 & 20.19 & 69.7 & 1 & 1 & 365 & 10720339 \\
\hline & Kosong & 1.10 & 20.19 & 69.7 & 1 & 1 & 365 & 564228 \\
\hline & & & Total & & & & & 130501045 \\
\hline
\end{tabular}

Tabel 9.

Hasil Perhitungan JSKN Tahun 2060

\begin{tabular}{|c|c|c|c|c|c|c|c|}
\hline kode & ket & LHR (2020) & jumlah sumbu & JSKNH & $\mathrm{R}$ & 365 & JSKN \\
\hline 1.1 & Total & 10 & 2 & 20 & 24.15 & 365 & 180.387 \\
\hline 1.2 & Total & 10 & 2 & 20 & 24.15 & 365 & 180.387 \\
\hline 1.1 & Total & 305 & 2 & 611 & 24.66 & 365 & 5.497 .090 \\
\hline $1.2 \mathrm{~L}$ & Total & 309 & 2 & 617 & 24.66 & 365 & 5.556 .411 \\
\hline \multirow{2}{*}{$1.2 \mathrm{H}$} & Total & 97 & 2 & 193 & 24.66 & 365 & 1.740 .086 \\
\hline & Kosong & 30 & 2 & 59 & 24.66 & 365 & 533.890 \\
\hline \multirow{2}{*}{1.22} & Total & 124 & 2 & 248 & 24.66 & 365 & 2.234 .429 \\
\hline & Kosong & 14 & 2 & 29 & 24.66 & 365 & 257.058 \\
\hline \multirow{2}{*}{$1,2-2$} & Total & 21 & 3 & 63 & 24.66 & 365 & 563.551 \\
\hline & Kosong & 15 & 3 & 46 & 24.66 & 365 & 415.248 \\
\hline $1,22+22$ & Total & 0 & 4 & 0 & 24.66 & 365 & - \\
\hline $1,22-222$ & Total & 112 & 3 & 336 & 24.66 & 365 & 3.025 .377 \\
\hline \multirow{2}{*}{$1,2-22$} & Total & 19 & 3 & 56 & 24.66 & 365 & 504.229 \\
\hline & Kosong & 9 & 3 & 26 & 24.66 & 365 & 237.284 \\
\hline \multirow{3}{*}{$1,2+22$} & Total & 21 & 4 & 83 & 24.66 & 365 & 751.401 \\
\hline & Kosong & \multirow{2}{*}{\multicolumn{2}{|c|}{ Total }} & 4 & 24.66 & 365 & 39.547 \\
\hline & & & & & & & 21.716 .375 \\
\hline
\end{tabular}

pribadi.

d. Data harga satuan pokok kegiatan (HSPK) yang digunakan untuk menentukan besarnya rencana anggaran biaya.

\section{Tahap Analisis}

Ada beberapa analisis dalam Studi ini, diantaranya:

1. Analisis Nilai Kerusakan Jalan

2. Analisis Volume dan Karakteristik Lalu Lintas

3. Analisis Tebal Struktur Perkerasan

4. Analisis Rencana Anggaran Biaya dan Biaya Pemeliharaan

5. Pemilihan Jenis Perkerasan

\section{E. Bagan Alir}

Secara skematis, alur kegiatan yang dilakukan pada Studi kali ini ditunjukkan pada Gambar 3 dan Gambar 4.

\section{HASIL DAN PEMBAHASAN}

\section{A. Analisis Penilaian Kondisi Kerusakan Jalan}

Dalam penilaian kondisi kerusakan jalan dilakukan penilaian kondisi kerusakan jalan berdasarkan pada total distresspoint atau dari data hasil survei nilai kerusakan jalan [3]. Kerusakan jalan meninjau mengenai jenis kerusakan, kualitas dan besarnya kerusakan jalan yang terjadi. Pada waktu pengamatan dilapangan juga dilakukan pencatatan atas jenis kerusakan pada perkerasan yang ditinjau. Selain itu juga dilakukan survei terhadap kondisi drainase yang ada pada ruas jalan tersebut. Peninjauan sistem drainase dititik beratkan pada luas genangan air banjir di permukaan jalan, kondisi saluran tepi, frekuensi banjir, dan lamanya terjadi genangan sampai surut.

1. Survei Kerusakan Visual

Untuk mengetahui kerusakan perkerasan jalan secara visual, survei ini dilakukan setiap segmen 250 meter.

Berikut contoh perhitungan nilai kerusakan jalan [3], sebagai berikut :

Nama ruas jalan : Ruas Jalan Mercedes Benz

Panjang ruas jalan : 3400 meter

Segmen : 1/tiap 250 meter

Penilaian kerusakan jalan dengan persamaan 1 dibawah ini. $\frac{\text { Luas Kerusakan }}{\text { Luas Segmen }} \times 100 \%$

Misalnya seperti penilaian presentase kerusakan pada segmen 10 adalah Potholes (berlubang) dengan perhitungan :

Luas Kerusakan : Panjang = 5,8, 22, dan 23 meter

: Lebar $=6,4,3,5$, dan 2,72 meter

Luas Jalan : Panjang $=250$ meter

$$
: \text { Lebar }=7 \text { meter }
$$

Maka :

176,68

$\frac{176,68}{2000} \times 100 \%=10,096 \%$ (masuk kategori $10-30 \%$ )

Ada beberapa jenis kerusakan dengan faktor pengali masingmasing jenis kerusakan tersebut yang ditunjukkan pada Tabel $1[3]$.

Kategori kerusakan Potholes (Kategori I) yang termasuk golongan 10-30\%, memiliki nilai presentase kerusakan yaitu 6 (kondisi wajar atau cukup). Nilai dari presentase tersebut nantinya akan dikalikan dengan faktor pengali berdasarkan 


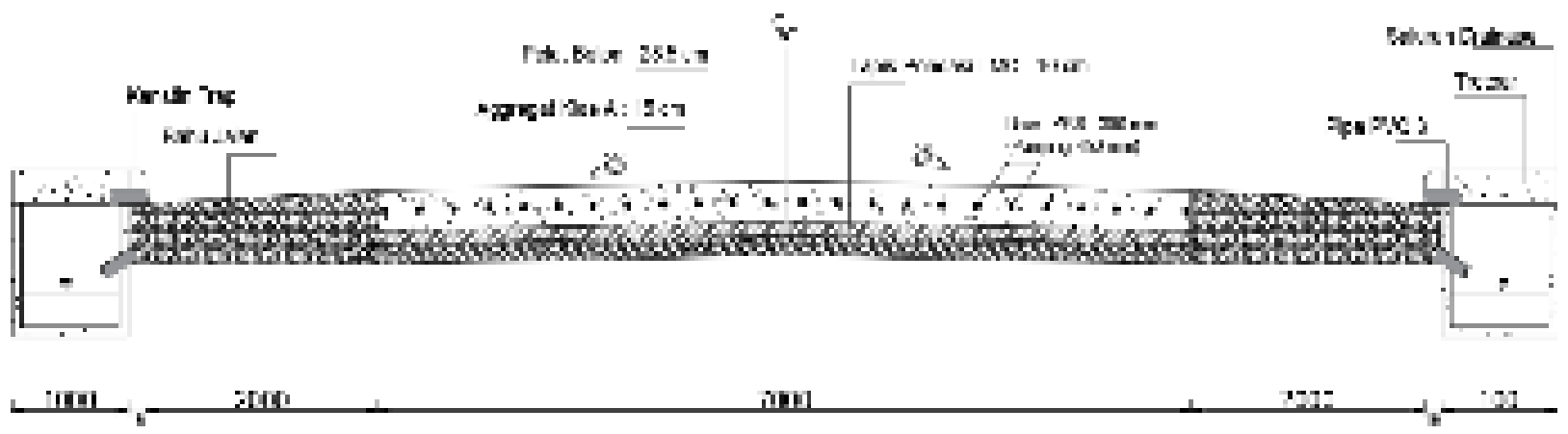

Gambar 5. Tebal Sturktur Perkerasan Kaku.

jenis kerusakan. Berikut merupakan contoh perhitungan dengan jenis kerusakan potholes pada segmen 10 :

- Termasuk kategori 10-30\% dengan nilai 6

- Faktor pengali : 6

Maka, nilai kerusakan untuk jenis Potholes

Nilai Kerusakan $=$ Extent $(10-30 \%) \times$ Nilai Faktor Pengali

$$
=6 \times 6-\rightarrow 36
$$

Dari hasil survei tersebut dapat langsung dimasukkan pada formulir survei seperti Tabel 2.

2. Survei Riding Quality (RQ)

Survei ini bertujuan untuk mengetahui tingkat kenyamanan permukaan jalan oleh pengguna kendaraan. Penilaian RQ dikelompokkan menjadi 5 (lima) kategori sesuai Tabel 3.

Survei Riding Quality dilakukan oleh 1 orang surveyor dengan mengendari kendaraan roda 4. Dan mencatat tingkat kenyamanan pada tiap segmen.

\section{Survei Kondisi Drainase}

Survei ini dilakukan untuk mengetahui kinerja drainase yang sangat berpengaruh terhadap kerusakan jalan. Contoh perhitungan nilai kondisi drainase pada segmen 10 dapat dilihat pada Tabel 4.

\section{B. Analisis Karakteristik Lalu Lintas}

Volume lalu lintas pada Studi kali ini merupakan data primer hasil survei yang dilakukan langsung di lokasi studi pada jam $06.00 \mathrm{~s} / \mathrm{d} 18.00$ WIB dengan mengklasifikasikan kendaraan menjadi 15 golongan [4]. Berikut hasil survei dapat dilihat pada Tabel 5.

\section{Faktor Pertumbuhan Lalu Lintas}

Meramalkan faktor pertumbuhan lalu lintas berkaitan langsung dengan kondisi kapasitas jalan sesuai umur yang direncanakan. Pada pertumbuhan lalu lintas ini menggunakan beberapa data pendukung yaitu laju pertumbuhan tahunan jumlah penduduk, PDRB, dan PDRB per Kapita Kabupaten Bogor [6]. Seperti ditunjukkan pada Tabel 6.

Sebelum menghitung faktor pertumbuhan lalu lintas, perlu dihitung dahulu kapasitas jalan perkotaan dengan rumus :

$\mathrm{C}=\mathrm{Co} . \mathrm{FC}_{\mathrm{LJ}} \cdot \mathrm{FC}_{\mathrm{PA}} \cdot \mathrm{FC}_{\mathrm{HS}} \cdot \mathrm{FC}_{\mathrm{UK}}$

$=2900 \times 1,00 \times 1 \times 0,88 \times 1,04=3026 \mathrm{skr} / \mathrm{jam}$

Maka kapasitas Jalan Mercedes Benz adalah 3026 skr/jam

Sedangkan prediksi jumlah kendaraan dengan umur rencana 20 tahun dan 40 tahun dengan data yang sudah didapatkan melalui survey LHR pada tahun 2019 dihitung dengan contoh seperti berikut :

Kendaraan Berat (Truk 1.22)

$$
\begin{aligned}
\text { LHR } 2059 & =(1+\mathrm{i})^{\mathrm{n}} . \text { LHR } 2019 \\
& =(1+0,0986)^{41} \cdot 113=5333 \text { kendaraan } \\
\text { Skr/jam } & =\frac{\text { LHR } 2060}{24 \text { jam }}=\frac{5333}{24}=222 \mathrm{skr} / \mathrm{jam}
\end{aligned}
$$

Maka, jumlah kendaraan truk (1.22) pada tahun 2060 adalah 222 skr/jam. Untuk hasil selengkapnya dapat dilihat pada Tabel 7.

Hasil perhitungan menunjukkan bahwa jumlah kendaraan pada tahun 2060 sebanyak 11606 skr/jam dan sudah melebihi kapasitas jalan sebesar $3026 \mathrm{skr} / \mathrm{jam}$. Maka, perhitungan faktor pertumbuhan lalu lintas menggunakan rumus :

Untuk umur rencana 40 tahun

$R=\frac{(1+0,01 \cdot 0,0231) 40-1}{0,01.0,0231}+(40-24)(1+0,01.0,0231)^{(24-1)}$

$R=24,15$

Untuk umur rencana 20 tahun

$R=\frac{(1+0,01 \cdot 0,0986) 20-1}{0,01 \cdot 0,0986}=20,19$

\section{Vehicle Damage Factor (VDF)}

Pada Studi ini menggunakan 2 pendekatan yaitu nilai VDF dari perhitungan manual dan nilai VDF Tabel sesuai MDPJ 2017 [5]. Dan pada Studi ini digunakan VDF Tabel karena memiliki hasil yang lebih tinggi.

\section{E. Cumulative Equivalent Single Axle Load (CESAL)}

Tebal struktur perkerasan sangat dipengaruhi oleh jumlah beban yang diterima tiap sumbu. Untuk merencanakan tebal struktur perkerasan lentur perlu dihitung CESAL dengan persamaan (2) dibawah ini.

$\mathrm{CESAL}=\Sigma\left(\mathrm{LHR}_{\mathrm{JK}} \times \mathrm{VDF}_{\mathrm{JK}}\right) \times 365 \times \mathrm{DD} \times \mathrm{DL} \times \mathrm{R}$

Dimana :

ESATH-1 : kumulatif lintasan sumbu standar ekivalen

LHRJK : lintas harian rata - rata tiap jenis kendaraan niaga (satuan kendaraan per hari).

VDFJK : Faktor Ekivalen Beban tiap jenis kendaraan niaga.

DD : Faktor distribusi arah

DL : Faktor distribusi lajur

CESAL : Kumulatif beban sumbu standar ekivalen

$\mathrm{R} \quad$ : Faktor pertumbuhan lalu lintas

Dan hasil perhitungan CESAL dapat dilihat pada Tabel 8.

\section{F. Nilai California Bearing Ratio Rencana}

Dalam Studi ini nilai CBR diasumsikan $>6 \%$ tanpa perbaikan tanah dasar Untuk subgrade memiliki CBR sebesar $65 \%$, untuk subbase memiliki CBR sebesar $75 \%$. Sedangkan untuk base memiliki CBR 100\%.

\section{G. Perencanaan Tebal Perkerasan Lentur}

Dengan nilai CESAL sebesar 130.501.045. Maka tebal perkerasan lentur menggunakan cement treated base (CTB) sesuai MDPJ 2017 [5] yaitu AC-WC $5 \mathrm{~cm}$, AC-BC $6 \mathrm{~cm}, A C-$ Base $16 \mathrm{~cm}$, CTB $15 \mathrm{~cm}$, dan Pondasi Agregat Kelas A 15 $\mathrm{cm}$. 


\section{H. Perencanaan Tebal Perkerasan Kaku}

Digunakan rumus JSKN sebagai acuan perhitungan untuk menentukan tebal perkerasan kaku sesuai persamaan (3). JSKN = (LHR $x$ Jumlah Sumbu Kendaraan $) \times \mathrm{R} \times 365$

Dengan persamaan (3), perhitungan JSKN dapat dilihat pada Tabel 9 untuk menentukan tebal struktur perkerasan kaku.

Sehingga tebal perkerasan kaku dengan total JSKN sesuai Tabel MDPJ 2017 [5] adalah Lapis Drainase 10,5 cm, Lapis Pondasi LMC $10 \mathrm{~cm}$, dan Pelat Beton $28,5 \mathrm{~cm}$.

Dengan perencanaan tulangan menggunakan perkerasan kaku bersambung tanpa tulangan [7], perhitungan seperti ini: Kedalaman sambungan $=0,5 \times$ Pelat Beton

Jarak sambungan

$$
=0,5 \times 285=142,5 \mathrm{~mm}
$$

Diameter ruji

Panjang ruji

$$
=5 \mathrm{~m}
$$$$
=36 \mathrm{~mm}
$$$$
=45 \mathrm{~cm}
$$$$
=30 \mathrm{~cm}
$$

Jarak antara ruji

Bars $16 \mathrm{~mm}$ dan jarak $750 \mathrm{~mm}$. Gambar struktur perkerasan kaku seperti pada Gambar 5.

\section{Rencana Anggaran Biaya dan Biaya Pemeliharaan}

Perhitungan RAB perkerasan jalan pada Studi kali ini menggunakan HSPK Kabupaten Bogor hasil perhitungan sesuai panduan Peraturan Menteri PUPR Nomor 28/PRT/M/2016 Tentang Analisa Harga Satuan Pekerjaan Bidang Pekerjaan Umum [8]. Setelah mengetahui HSPK permasing-masing jenis pekerjaan maka kemudian dihitung RABnya. Seperti ditunjukkan pada contoh berikut ini :

Lapis Perkerasan AC Base

Volume $=$ Tebal $_{(\text {AC-BASE) }} \times$ Panjang $_{(\text {Jalan) }} \times$ Lebar $_{(\text {Jalan })}$ $=0,16 \times 3400 \times 7 \times 2,3$

$$
=8758,4 \mathrm{~m}^{3}
$$

HSPK Pekerjaan $=\operatorname{Rp} 860.751,-$

Total Biaya $\quad=\operatorname{Rp} 7.538 .801,-$

Hasil perhitungan anggaran biaya untuk masing-masing jenis perkerasan sebagai berikut :

Perkerasan Lentur $=\operatorname{Rp} 6.796 .491,-$ per meter kubik Perkerasan Kaku $=$ Rp 3.722.269,- per meter kubik

Dengan biaya pemeliharaan untuk perkerasan lentur adalah 5\% dari initial cost, dan perkerasan kaku adalah $1 \%$ dari initial cost. Maka hasil biaya pemeliharaan sebagai berikut:

Perkerasan Lentur $=\operatorname{Rp} 2.915 .539,-$ per meter kubik/tahun Perkerasan Kaku $=$ Rp 638.793,-- per meter kubik/tahun

\section{J. Pemilihan Jenis Perkerasan}

Pemilihan jenis perkerasan berdasarkan tebal struktur yang lebih tipis, anggaran biaya lebih rendah, dan biaya pemeliharaan yang lebih rendah. Maka rekomendasi jenis perkerasan yang sesuai untuk Jalan Mercedes Benz adalah perkerasan kaku (rigid pavement) dengan umur recanan 40 tahun.

\section{KESIMPULAN}

\section{A. Kesimpulan}

Berdasarkan analisis yang telah dilakukan, diperoleh kesimpulan sebagai berikut:

1. Secara umum kondisi lalu lintas atau karakteristik lalu lintas pada Jalan Mercedes Benz saat ini didominasi oleh motor dan mobil. Untuk kendaraan yang paling dominan melintas dan mempengaruhi kondisi perkerasan jalan adalah truk trailer (golongan 7c.3) yang memiliki presentasi
0,56\% dari total 27264 kendaraan/hari yang melintas di kedua arah Jalan Mercedes Benz ini.

2. Dari hasil survey dan analisis pada kondisi eksisting Jalan Mercedes Benz. Tingkat kerusakan jalan (D\&M 1990) pada Jalan Mercedes Benz ini didapatkan nilai rata-rata untuk kerusakan jalan adalah 49,93 dan jalan tersebut dikategorikan sudah mengalami kerusakan yang cukup kritis, beberapa ruas mengalami kerusakan yang cukup parah sehingga membutuhkan segera penanganan atau pemeliharaan tingkat sedang. Sedangkan untuk nilai drainase pada Jalan Mercedes Benz adalah 13,29 dan drainase pada jalan tersebut dikategorikan masih dalam kondisi sedang, dan fasilitas drainase memerlukan pemeliharaan ringan

3. Total tebal struktur perkerasan lentur adalah $57 \mathrm{~cm}$ dengan kombinasi tebal terdiri dari AC-WC $5 \mathrm{~cm}, \mathrm{AC}-\mathrm{BC}$ $6 \mathrm{~cm}$, AC Base $16 \mathrm{~cm}$, CTB $15 \mathrm{~cm}$ dan Pondasi Agregat Kelas A $15 \mathrm{~cm}$.

4. Total tebal struktur perkerasan kaku adalah 53,5 cm dengan kombinasi tebal terdiri dari lapis drainase $15 \mathrm{~cm}$, lapis pondasi LMC $10 \mathrm{~cm}$, dan tebal pelat beton $28,5 \mathrm{~cm}$.

5. Biaya awal konstruksi selama 40 tahun untuk perkerasan lentur sebesar Rp 6.796.491/- per meter dengan biaya pemeliharaan Rp 2.915.539,- per meter dan per tahunnya. Dan biaya awal konstruksi selama 40 tahun untuk perkerasan kaku sebesar Rp 3.722.269,-- per meter dengan biaya pemeliharaan sebesar Rp 638.793,- per meter dan per tahunnya.

6. Jenis perkerasan yang sesuai untuk perbaikan perkerasan di Jalan Mercedes Benz, Kecamatan Gunung Putri, Kabupaten Bogor, Jawa Barat adalah Perkerasan Kaku (Rigid Pavement) dikarenakan tebal konstruksi yang lebih tipis, biaya konstruksi yang lebih murah, dan biaya pemeliharaan yang lebih murah. Sehingga perkerasan kaku (rigid pavement) sangat sesuai untuk perbaikan perkerasan di Jalan Mercedes Benz.

\section{B. Saran}

Berdasarkan analisis yang telah dilakukan, didapatkan beberapa saran yaitu :

1. Diperlukan ketelitian lebih terhadap survei primer yang sangat berpengaruh pada hasil Studi ini.

2. Diperlukan data CBR yang sesuai dengan kondisi di lapangan agar hasil dari $\mathrm{S}$ ini lebih maksimal.

3. Diperlukan data HSPK Kota/Kabupaten yang berasal dari pemangku kepentingan setempat. Sehingga perencanaan anggaran biaya yang dihitung bisa sesuai dengan kondisi harga satuan di lokasi studi yang bersangkutan.

\section{UCAPAN TERIMA KASIH}

Terima kasih kepada Badan Pusat Statistika atas data yang sudah disediakan. Serta kepada PT Wijaya Karya, Persero, Tbk yang sudah memberikan bantuan dana untuk Studi ini.

\section{DAFTAR PUSTAKA}

[1] Pemerintah Republik Indonesia, "Undang-Undang Nomor 22 Tahun 2011 Tentang Lalu Lintas dan Angkutan Jalan,” 2011.

[2] S. Sukirman, Perkerasan Lentur Jalan Raya. Bandung: NOVA, 1999.

[3] D. Dirgolaksono, Metode Penilaian Kerusakan Jalan di Indonesia. Surabaya, 1990

[4] Departemen Pekerjaan Umum, "Modul RDE-08: Rekayasa Lalu 
lintas," 2005.

[5] Direktorat Jenderal Bina Marga, "Manual Desain Perkerasan Jalan, Nomor 04/SE/Db/2017 ed," Jakarta, 2017.

[6] Badan Pusat Statistik Kabupaten Bogor, "Data Jumlah Penduduk Kabupaten Bogor,” bogorkab.bps.go.id, 2019. [Online]. Available: https://bogorkab.bps.go.id/dynamictable/2019/03/05/21/pendudukkabupaten-bogor-tahun-2018-2019.html.
[7] Direktorat Jenderal Pemukiman dan Prasaran Wilayah, "Pd T-14-2003Perencanaan Perkerasan Jalan Beton Semen,” Jakarta, 2003.

[8] Kementerian Pekerjaan Umum dan Perumahan Rakyat, "Peraturan Nomor 28/PRT/M/2016 Tentang Analisis Harga Satuan Pekerjaan Bidang Pekerjaan Umum,” Jakarta, 2016. 